\title{
Higher education, unbundling and the end of the university as we know it
}

\author{
Tristan McCowan \\ (Institute of Education, University College London) \\ Published in Oxford Review of Education, 2017 \\ DOI: $10.1080 / 03054985.2017 .1343712$
}

\begin{abstract}
Unbundling is the process through which products previously sold together are separated into their constituent parts. In higher education, this dynamic has been driven primarily by financial motivations, and spearheaded by the for-profit sector, but also has pedagogical motivations through its emphasis on personalization and employability. This article presents a theoretical analysis of the trend, proposing new conceptual tools with which to map the normative implications. While appearing to offer the prospect of financial viability and increased relevance, unbundling presents some worrying signs for universities: first, the removal of possible synergies between teaching and research, and between different modes of learning; second, the undermining of the ability of institutions to promote the public good and ensure equality of opportunity; and third, the threat of hyperporosity to the conducting of basic research with long-term benefits.
\end{abstract}

\section{Keywords:}

commodification; for-profit higher education; future of the university; MOOCs; unbundling

\section{Introduction}

The challenges of funding the continuing expansion of higher education, and concerns about its lack of alignment with the contemporary economy, have led to an incipient dynamic of 'unbundling', fuelled by the growth of the for-profit sector (Robertson \& Komljenovic 2016a; 2016b). This process involves the separating out of the institution into its constituent roles and different activities, and the cutting away of functions perceived to be superfluous, allowing the customer to purchase only those elements desired. The merits or threats presented by this trend are hotly contested. On one side of the argument are those who assert the desirability or inevitability of this disruptive innovation' (Christensen et al. 2011), asserting that "Education will never be the same: unbundled, less costly and more effective" (Litan 2015). On the other are those who defend the traditional university, seeing unbundling as an unprecedented threat to the institution, potentially leading to a shift as radical as the dissolution of the monasteries in $16^{\text {th }}$ century Britain. 
Unbundling is occurring in the context of increasing difficulties for nation-states to finance the expanding enrolments of higher education through taxpayer funds, and the consequent spiralling costs for students and their families. According to Herk (2015), in the USA, "By the end of 2014, total student loan balances reached $\$ 1.3$ trillion, more than tripling since 2004", and these loans are widely believed to be developing into the next subprime mortgage crisis. Craig (2015) captures this escalation of costs through the image of the 'lazy river' - the luxury water feature in which bathers are pushed gently by the current around a winding circular pool - one of a number of attractions that universities are investing in so as to attract prospective students.

Universities cannot help but hear these criticisms, but in the context of robust demand for their services, the pressures for change have been relatively easy to ignore. For the most part, universities have tried to 'have their cake and eat it' by marketising access to their products, while maintaining many of their traditional activities that have a less direct economic impact. However, there are signs that the rug is about to be pulled firmly from beneath their feet. At least, that is what is argued by works such as the widely circulated An Avalanche is Coming (Barber et al. 2013), according to which, universities need to reinvent themselves or cease to exist. The challenges of rising enrolments, spiralling costs and need for adaptation to a changing global economy, mean that universities must become leaner, more efficient engines of innovation, strongly connected to local industry. If they do not, they will be slowly picked off by the new 'upstarts': for-profit providers able to offer specific services at a much cheaper price for the consumer.

The process of unbundling is already underway, as evidenced in a range of phenomena, most famously the massive open online courses (MOOCs) that have grown rapidly since Sebastian Thrun and Peter Norvig ran the pioneering course on artificial intelligence at Stanford in 2011. Other manifestations include the separation of professionals engaged in course design and delivery (particularly in online courses), the growth of teaching-only institutions, the development of cheaper 'no-frills' courses, and reduction in the proportion of tenured staff. These changes come in the context of broader scepticism about the appropriateness of conventional education institutions for the new realities of the economy, leading to the emergence of Uncollege, the Thiel Foundation, and other organizations promoting alternatives to university study - advocating a kind of Silicon Valley deschooling (McCowan 2016a).

However, seen in the context of global higher education as a whole, these manifestations of unbundling are still far from universal: for the most part, the university continues in its bundled form, albeit with some significant changes on account of marketization (Bok 2003). As argued by Marginson (2016a), there are also forces at play that serve to reinforce the integration of the university, particularly in the case of high ranking institutions. The integrated research university still remains the 'gold standard', and the fever around achieving 'world-class' status, and inserting institutions into the top echelons of the international rankings, provides isomorphic pressures towards the traditional campus institution bringing together elite research, teaching, extracurricular activities and graduate studies. The process of unbundling is, therefore, an incipient one, and concentrated in a few countries. Nevertheless, the likelihood is that it will spread and accelerate, in particular in light of its close link with the for-profit sector, in which much 
current HE expansion is located, and the transnational nature of many for-profit companies.

This article presents a theoretical analysis of the process of unbundling in higher education. The purpose here is not to predict whether the days of the university are really numbered, or the extent to which and speed at which unbundling may in fact happen. Instead, the aim is to draw out the implications of the potential unbundling of higher education, so as to map the normative terrain, and to evaluate the claims made by its advocates. To what extent would an extension of unbundling to a systemic level represent a threat to the quality and integrity of the functions of teaching, research and community engagement? Would it undermine and ultimately destroy the positive contribution of university to society and to the lives of individuals? Or could these functions just as well be realized in separation from one another and performed by different organizations and individuals? In short, should we really be worried about the end of the university at all?

There is as yet relatively little academic work on unbundling. An early analysis from a legal perspective was carried out by Wang (1975), asserting the possibility of applying anti-trust laws to the packaging of what were considered to be the four key functions of universities: impartation of information, accreditation, coercion and club membership. Universities could be seen as unjustified in 'tying' these products together: for example, by obliging students only seeking accreditation to also attend lectures. Troutt (1979) then applied these ideas to faculty work, distinguishing instruction, assessment and advising as separate activities that could be carried out by different professionals. It is only in the decade of the 2010s, however, that the issue has attracted significant public attention. While there has been a fair amount written on the phenomenon in recent years, much is comprised of popular accounts of the crisis of higher education (e.g. Selingo 2013), or alternatively takes an advocacy standpoint, written by those with a personal involvement in the process (for example, Ryan Craig [2015], who is founder and managing director of University Ventures, an investment company for private higher education; or Ananta Agarwal [2013] CEO of edX, Harvard and MIT's joint MOOC platform). The rigorous research and analysis available (e.g. Gehrke \& Kezar 2015; Macfarlane 2011) has tended to focus on the changing nature of academic work and the faculty role.

Empirical research on unbundling is still lacking, therefore, but there is also a critical need for a broader theoretical analysis. In order to draw out the salient dimensions of unbundling, the article draws on the theoretical framework of value, function and interaction (outlined in McCowan 2016b), but also develops new theoretical tools and perspectives as a means of clarifying the terrain of the current debate. For purposes of illustration it also draws on a range of empirical contexts, primarily the USA on account of being the location for the most advanced forms of unbundling, but also Brazil, the UK and Rwanda. It builds on a discussion of unbundling in a previous analysis of the post2015 international development agenda (McCowan 2016b), as well as engaging with the small number of existing academic studies on the topic, and a range of journalistic accounts. The aim of this article is to provide a broader conceptual mapping of the phenomenon than appears in existing accounts, focusing not only on the financial dimensions and implications for the survival and viability of the institution, but also for its fundamental purpose in furthering human understanding, and for issues of equality and social justice. 


\section{What is unbundling?}

Products are commonly sold to us in bundles. In some cases, these bundles are made up of distinct items which all need to be in place in order for the consumer to enjoy the good or service being sold. Take for example an IKEA bookshelf, which comes together as a collection of frame, shelves, screws, nails and so forth. In other cases, a bundle may be made up of products that are not interdependent, and that could be used separately, but there is a perceived cost or convenience benefit to buying them together, as in the case of a media package - involving television, telephone and broadband. In some cases, producers package a number of similar products together in order to ensure financial viability of production, thereby forcing consumers into buying products they do not want: Craig (2015) gives the example of the music album in the pre-digital era, through which (while some songs were also available as singles) consumers were encouraged to purchase a range of little-known tracks in addition to the chart toppers.

In this article, I will employ the terms 'interrelated bundle' to refer to the first type, when all items are required for the good to be enjoyed; 'convenience bundle' to the second, when the bundle functions in the interests of consumers to save them time and possibly money; and 'tie-in bundle' for the third, in which producers force consumers to buy unnecessary goods for their own financial benefit. In some cases, therefore, bundles serve the interests of consumers: the popularity of package holidays, for example, continues, since the complexity of multiple bookings is reduced, at low cost. However, in other cases consumers may not benefit, or indeed may be priced out of the market altogether, and it is these that have led to the process of 'unbundling'. If an opening is made for the constituent components to be sold separately at a lower cost, consumer allegiance will shift rapidly.

According to Gerhke and Kezar (2015: 96):

$[\mathrm{U}]$ nbundling is the differentiation of tasks and services that were once offered by a single provider or individual (i.e. bundled) and the subsequent distribution of these tasks and services among different providers and individuals.

We can distinguish between two types of unbundling. First, is where a group of distinct products that were previously sold together are now dispensed separately (here termed 'disaggregation'). For example, movements in the music industry away from the 'album' towards the purchasing of individual tracks, or streaming without a direct cost. Second, is the 'no-frills' model, in which the basic product is sold in its barest form, divest of extras and trappings. Amongst the most successful examples of this second type of unbundling is the rise of the low-cost airline from the 1990s. By paring down the experience of flying to its bare essentials - without meals, luggage allowance, and using cheaper airport locations - costs were bought down significantly, thereby displacing traditional airlines on many short-haul routes. In many cases consumers have flocked to these new options as they are willing to sacrifice the extra comfort and convenience for the vastly reduced price, or are able to purchase the desired products with greater precision without unwanted ones. 
In the no-frills model, therefore, the consumer receives only part of the original bundle, dispensing with the non-essential parts. In disaggregation, all of the parts may still be consumed, but acquired from different producers. These two models of unbundling can take place in each of the three cases of interrelated, convenience and tie-in bundles - but with different implications in each case. As will be explored further, it is mainly in cases of interrelated products that unbundling presents problems.

How do these phenomena manifest themselves in higher education? Clark Kerr's (1963) classic work, The Uses of the University presented the notion of the 'multiversity', the apex of bundling in higher education, an extraordinarily multifaceted conglomeration of diverse institutes, faculties, functions, services and people. While not all universities have reached this size and complexity, the research university with its activities of teaching, research and service still represents the global standard of institution, and the starting point for the process of unbundling. However, we are not here faced with a simple monodirectional trajectory from bundled to unbundled. As shown by Gehrke and Kezar (2015), unbundling is not a new phenomenon, and there have been moves towards and away from different forms of bundle throughout the history of higher education. Indeed, the bundling of teaching and research only took place in the $19^{\text {th }}$ century, and there have been significant fluctuations in the roles pertaining to academic staff, with the pastoral role, for example, periodically emerging and receding from view. Furthermore, there has not always been a coexistence of instruction and assessment (Anderson 2006): new universities created in England in the $19^{\text {th }}$ and early $20^{\text {th }}$ centuries commonly had their degrees validated by existing institutions, and the University of London awarded degrees for overseas colleges such as Nairobi, Dar es Salaam and Makerere. Nevertheless, the current trends in unbundling are far more radical than the previous ones, and a greater challenge to our assumptions about the higher education institution.

We can distinguish between four levels at which unbundling in higher education can be conceptualized:

1. Higher education systems

2. Institutions

3. Courses

4. Academic staff

First, we can think of the entirety of the system becoming separated out. In this sense, the existence of a coordinated system involving a range of different institutions fulfilling a common purpose is lost, and instead there are individual institutions in a disjointed existence. (The decline of one of the best examples of a coordinated system - the California Master Plan - has been discussed by Marginson [2016b]). This level, however, is rarely analysed as part of the phenomenon of unbundling, and is usually conceptualized in different terms. For the most part, discussions of unbundling relate to the institutional level, and this is the level at which it will be discussed in this article, along with the sublevels of course and lecturer.

The institution of university can become unbundled, as discussed above, through its functions being separated out and conducted by distinct organizations. An obvious manifestation of unbundling - and one that has been in evidence for some time - is outsourcing of services within universities such as catering, cleaning, ICT, library services and accommodation. It is important to highlight that this trend is not exclusive to private 
universities, and in many countries is now the norm in public institutions. While this outsourcing is often to external companies, in some cases universities have established their own firms, as is the case of FX Plus, created by Falmouth University and the University of Exeter in the UK to provide support staff, including academic support (Grove 2013). There is also a clear locational element, with challenges to the idea of the university as 'place', with the emergence of multiple campuses, or hubs replacing campuses, or with students studying at a distance in any part of the world. Following from the early success of the Open University in the UK, there has been a huge expansion of distance providers, with institutions such as the Indira Gandhi National Open University in India and the Allama Iqbal Open University in Pakistan having student numbers in the millions.

An integral part of the process is the unbundling of taught courses and academic work. In the case of the former, the design, delivery and assessment of the course may be conducted by different institutions. A case in point here is the emergence of alternative providers of validation of knowledge, and the likelihood of companies such as Pearson in taking up an increasingly significant role in the assessment of competencies in particular areas (with learners awarded a series of discrete badges, rather than a single coordinated degree). In the area of online courses, there is a common separation between course design and delivery. Unbundling, therefore, signals the end of the programme of study, in which academics curate learning through a process of selection and sequencing of knowledge content. MOOCs are the most obvious manifestation of this form of unbundling, and have grown rapidly, although without yet bringing the revolution that was at first imagined by some.

These changes inevitably lead to shifts in the role of academic staff. As explored by Macfarlane (2011), the 'all-round' academic is being progressively replaced by 'paraacademics' such as "skills advisers, educational developers, learning technologists and research management staff" (p.59), with a deskilling of the former and an upskilling of the latter. These shifts - evident in public as well as private institutions - have been linked to the growth in the proportion of non-tenured faculty, most prominently in the USA. Developments in ICT have facilitated relatively easy broadcasting of lectures and other communications, enabling students in multiple locations to have contact with the ideas of well-known academics (Paulson 2002). These 'stars' (Barber et al. 2013) are not, of course, able to have actual interactions with students, thus opening the door to a supplementary group of tutors who service the students' pedagogical needs. This trend would inevitably signal the end of the university professor, in the role most famously promoted by Wilhelm von Humboldt, as one who engages in the pursuit of knowledge and simultaneously supervises students in their own pursuit. Commentators have also linked these changes in academic faculty to the decline of collegiality and democratic governance in universities (Macfarlane 2011).

There is also a 'no-frills' model of higher education. In order to combat the escalating costs outlined above, providers (many of which for-profit) have emerged in many countries offering degrees at a low cost, but with limited pedagogical interaction and access to resources, and without the broader enrichment activities characteristic of the campus university experience. Many of these institutions target working adults rather than school leavers, and offer evening courses, thereby opening higher education to populations who had previously struggled to access conventional institutions. In Brazil, 
for example, the private sector has grown exponentially since the late 1990s, through the opening of lower-cost evening courses: students can pay only $£ 50$ a month, compared to as much as $£ 2000$ a month for higher prestige institutions and courses, but must be content with 'high school' style instruction in classroom hubs dotted around cities in high street locations and even shopping centres, with little in the way of library resources and autonomous study (McCowan 2004). In the USA, there are a range of experiences of this type. The University of Phoenix is a prime example in terms of the unbundling of the faculty role, standardization of the curriculum and use of blended mode (Kinser 2002), although many of these for-profit institutions directed at working adults actually charge more than public institutions. Coventry University in the UK has established 'Coventry University College', where students pay only half the cost of a regular degree, but are barred from accessing university facilities such as libraries and sports centres (Vasagar 2011). Beyond these forms, there is a further stage of unbundling displayed in cases in which an online platform is provided to coordinate students' learning, but without itself providing the content. Western Governors University, for example, which advertises itself as "half the cost of other online universities", does not provide instruction at all, but acts as a broker for courses provided by other institutions, offering assessments to certify competency (Paulson 2002). UniversityNow (2017), with a mission to "make a quality college education available and affordable to people everywhere", offers competencybased courses through its child institutions Patten and New Charter.

\section{Drivers for unbundling}

Universities have been described as the oldest European institution with the exception of the Catholic Church (de Ridder-Symoens 1996), and their ability to survive through the dramatic political, economic, social and scientific changes of the past eight centuries is testament to both the importance of their core role in society and their ability to adapt to changing circumstances. So why are there signs now of the unravelling of the institution? There are two broad drivers for contemporary processes of unbundling: financial and pedagogical. As will be seen below, these are not entirely discrete - for example, some of the pedagogical changes are intended to bring long-term economic benefits - but do represent distinct modes of justification.

Given the origins of unbundling in business, and the strong links to the for-profit sector in HE, the financial motivations are the most evident. These may relate either to the provider or the consumer, or both. For providers, efficiency savings can be made through unbundling, for example through changes in processes of course design, by centralising and standardising, and freeing up more academic staff time for delivery. Focusing on a specific piece of the puzzle can also create economies of scale for institutions. In some cases savings are made through the extraction of superfluous elements (i.e. the no-frills model) and possibly through a simple reduction in the quality of the product. These changes can drive up profits for education companies, and provide greater incentives for new providers to enter the market. While, there is not consensus that innovations such as online provision always represent a reduction in costs, there is certainly the potential for them to do so (Bowen 2013). Costs can be reduced through simplification of the provision, and thereby bring in new students who would have been excluded from the market in the context of conventional institutions. Some manifestations of unbundling most prominently MOOCs - are currently offered on a free of charge basis. Nevertheless, 
commercial MOOCs are starting to predominate (Dianati 2016), and even for the nonprofit courses, there is still a significant financial motivation for universities in terms of enhancing the visibility of their brand, while SPOCs (small private online courses) have also emerged in their wake.

There are also a range of arguments based on the desirability of unbundling for enhancing teaching and learning. According to this view, the conventional university is deficient in the preparation it provides for students, through lack of adaptation to the specific needs of contemporary society. There are two main pedagogical arguments put forward. First of these is personalization - that learners need to have a higher degree of control over their own learning, in terms of the content, process and timing. Second, that learning needs to be more attuned to the needs of the workplace and the demands of employers, particularly in the context of a rapidly changing labour market.

The primary vehicle for achieving both of these ends is through the movement from structured degrees and courses to competencies. Craig (2015) and others write disparagingly of the reliance of traditional universities on 'seat time', credits based at least in part on compulsory course attendance. Instead, students should piece together a range of different competencies, areas of knowledge and skill aligned with employer requirements, ideally managed via a competency management platform. Students should be able to acquire these competencies from a range of sources of learning, and have them assessed when they feel ready, allowing for the different rhythms of learning and other commitments of students. In addition to 'adaptive learning', unbundling is seen to facilitate gamification, the introduction of techniques from videogames to make learning more entertaining, to increase engagement and reduce dropout (Craig 2015). These changes, according to advocates, serve to make learning more relevant and engaging for the individual learner (personalization) and more attuned to the needs of the economy (employability).

These benefits are sometimes presented as a social justice justification for unbundling. The incentives for new providers to enter the market and the lowering of costs together lead to the conditions for expansion of access to higher education, while personalization and employability are seen to make HE more beneficial to disadvantaged students. The next section will assess the validity of these claims, along with a consideration of the potential impacts of unbundling relating to student learning, the role of the university in society, and issues of fairness and equality.

\section{Implications for value, function and interaction}

As outlined in McCowan (2016b), the institution of the university - and its changing nature across time and space - can be analysed in terms of three dimensions: value, function and interaction. The first of these refers to the kinds of values that are attributed to, or that motivate, the activities of the university - in particular, the extent to which knowledge is considered to have intrinsic or instrumental worth, and in the case of the latter, the form of instrumental benefit in question. So, for example, research can be valued variously as an intrinsically worthwhile pursuit of truth, or as part of long-term nation-building, or as a means of generating immediate economic benefits. 
'Function' refers to the activities carried out in and by the university: for example, teaching, research, public communication, archiving of knowledge and provision of services such as hospitals - varying in terms of the selection of roles taken on, in the emphasis given to each of them, and in the ways they are carried out. Finally, there is 'interaction', referring to the relationship between the institution and the society outside. Universities vary in their levels of porosity, with some being relatively resistant to the inward and outward flows of ideas and people, and others being more open to them.

These three dimensions allow us to unpick the significance of features of the university and changes in institutional models. The implications of unbundling for these three dimensions will be drawn out in the sections that follow.

\section{$\underline{\text { Value }}$}

It is important to emphasize from the outset that no university ever has a unitary set of values: there will always be some diversity of perspective (given the distinct groups of managers, lecturers, non-academic staff, students and external stakeholders). Nevertheless, we can still point to broad tendencies. There are three elements of significance for value that will be dealt with here: individualization, public good and affirmative action.

\section{a) Individualization}

Unbundling leads to a significant increase in individual choice over what is learned, and a corresponding decrease in lecturer and institutional stipulation of what is of value and why. This involves a personalization of learning - as discussed above - but also a deeper process of removal of the collective orientation of the institution in terms of vision and role.

The clearest implication of this process is that it leads to a fragmentation or multiplicity of values. While unbundling is largely associated with commercialization, the door is therefore left open to intrinsic as well as instrumental rationales for learning: for example, the MOOC phenomenon has involved people signing up for courses which provide no concrete benefit other than the acquisition of the knowledge in question. On the one hand, this implies a certain democratization in that the university becomes more responsive to the particular needs and goals of students - indeed, this democratization is heralded by unbundling's advocates. On the other hand, it leads to an undermining of collective values, and also of the possibility that there exist people who are more experienced and knowledgeable, and who might provide guidance for those less so - as occurred in the traditional course structured and sequenced by lecturers. (There may be some echoes here of the 2016 leitmotif 'post-truth', and the reaction against experts in recent popular votes).

b) Public good

The main proponents of unbundled higher education are for-profit companies, and many of the underlying drivers for the trend are commercial in nature. Nevertheless, as discussed above, an unbundled system does not necessarily lean on values purely of 
commercial exchange, and can involve various other instrumental and intrinsic rationales as well.

Nevertheless, there is a necessary negative impact of individualization on the ability of universities to promote public goods. Understood as non-rivalrous and non-excludable (in the plural sense [Marginson 2011]), these goods - for example, advances in recycling technology or archaeological knowledge of ancient civilizations - are unlikely to be promoted through individual demand, and require collective organization and investment. Cross-subsidization may be needed to support courses in the public interest, or state funding needed for publicly beneficial research. Understood in a singular sense as the public good or public sphere (Marginson 2011), the university's role is undermined by the disintegration of space for collective engagement and debate. In particular, the potential role of the university in bringing together people from diverse backgrounds (socio-economic, racial, ethnic, religious etc.) and fostering mutual understanding and respect is severely curtailed. The potential developmental role of universities in lowerincome countries, or in relation to marginalized groups in wealthier countries, is also threatened (McCowan 2016b; Coleman 1986).

\section{c) Affirmative action}

The value dimension of universities also includes their positions in relation to questions of fairness, equality and social justice. The implication of unbundling is that it reduces the leverage of institutions in this regard. (There are also significant implications for the leverage of the state at the national level.) While institutions do not always take advantage of the opportunity, the existence of an integrated institution and admissions system allow for the implementation of affirmative action policies to facilitate the entry and success of students from disadvantaged backgrounds. Of course, this kind of affirmative action is predicated on the existence of limited places - a constraint that may (theoretically at least) disappear in the context of an unbundled institution/system. As outlined above, a social justice argument can be made for unbundling on account of its potential for expanding access, with the provision through MOOCs and 'no-frills' courses of less costly, and in some cases free-of-charge study. Yet despite the initial promise, MOOCs have not substantially expanded access to knowledge for disadvantaged populations and countries, and have mostly been used by those who already have degrees, mainly based in high-income countries, and who are more likely to have the requisite learner autonomy (Wildavsky 2014). There are some exceptions: Kepler (2016) in Rwanda provides access to higher education for talented young women and men from disadvantaged backgrounds in the context of the rapidly developing post-conflict country, describing itself as 'the future of higher education'. The instruction at the university is entirely through MOOCs - a collection of different courses mainly from US providers - leading ultimately to a degree accredited by Southern New Hampshire University.

However, even if unbundling does lead to expanded access, it does not necessarily signify lessening of inequalities, given the likelihood of stratification. Inequalities of wealth, prior schooling, parental support and a host of other factors will still affect the quality of learning experience available and opportunities proffered subsequently - indeed, these inequalities may be exacerbated through the deregulated nature of the provision. In Brazil, for example, there has been significant expansion of the 'no-frills' institutional type 
- mainly through the for-profit sector. This has driven rapid increases in enrolments (with a staggering rise from approximately 1 million students in private institutions in 1998, to nearly $2 \frac{1}{2}$ million in 2002, and a steady increase to more than 5 million in 2013) primarily amongst the lower-middle classes who had previously been excluded (Schwartzman 2004; INEP 2015). Yet the poor quality of the learning experiences provided and the relatively low recognition of the degrees have meant little change in social inequalities (McCowan 2016c).

\section{Function}

The changes to the role and function of universities presented by unbundling have been laid out in the previous sections: they include a paring down of the diverse offerings and facilities leaving only the core activity of instruction; the separation of the primary functions of teaching and research into separate institutions, or dividing of these tasks between different staff members; moves away from the structuring of course content in full degree programmes; and a loss of the role of validating students' knowledge and skills. Taken to its ultimate length, unbundling results in the disintegration of these elements to the extent that we cannot meaningfully speak of a university at all. This section will focus on the potential ramifications of these changing functions. Some at least of what educational institutions do can be attributed to the convenience of having large numbers of people (often of the same age group) assembled in a single place: so for example schools are commonly used as spaces for immunization, nutrition enhancement programmes and so forth. Universities serve this function to some degree, in providing a locus for information to be provided on life opportunities, careers, HIV/AIDS prevention and so forth. Some of this unbundling can take place without significant impact on the core role of the university, while there are other instances that strike at the heart of the institution's function.

The implications of these changes are more numerous and complex than would be possible to deal with in a single piece. Instead, this section will focus on two of the most salient elements: first, the paring down of the pedagogical environment to basic instruction (relating to the 'no frills' mode of unbundling outlined above); and second, the separation of the elements of the multi-faculty research university (relating to 'disaggregation').

In response to the claimed pedagogical benefits of unbundling - personalization and employability - a range of limitations can be identified. A primary factor is that unbundled forms of teaching may not provide sufficient learner support. There is substantial research evidence that the fragmentation of the learning environment and learning support has a negative impact on learning, particularly for non-traditional students, and conversely of the positive impact of interactions with academic staff outside the classroom, for example through participation in research projects, or through seeking general advice and guidance (see Gehrke \& Kezar 2015). Furthermore, the portrayal of learning associated with unbundling is predominantly transmission-based, involving the acquisition of knowledge and skills through mono-directional absorption in isolated individuals. Unbundled pedagogy undermines the relational dimension of teaching and learning. The benefits of learning in a collective, of dialogue and certainly of Illich's (1973) more demanding conception of 'convivial' learning, are no longer available in this model. While the campus university may have some apparently unnecessary 
luxuries, the existence of extracurricular activities including artistic and sporting pursuits, political and social activities, are central to a holistic conception of learning particularly if we envisage higher education as a space for civic and personal, as well as vocational development. There are also questions relating to the curriculum, and the advantages of exposure to the whole of a canon within a disciplinary area, rather than a fragmented selection based on students' current interests. Finally, while it is not essential for universities to be the validators of knowledge, and other institutions may carry out this role effectively - there are advantages in integration of teaching and assessment, in opening possibilities for constructive alignment (Biggs 1999).

There is a strong attachment in university circles to the coexistence of teaching and research - an idea with its roots in the thought of Wilhelm von Humboldt. In some cases, the triad of teaching, research and community engagement are strongly defended as definitional of the university (for example in Latin America). In fact, empirical evidence is conflicting on the link between research and teaching activities (de Jonghe 2005; Gehrke \& Kezar 2015), with a prominent meta-review of 58 studies showing no significant link between excellence in the two areas (Hattie \& Marsh 1996). Nevertheless, this finding may be an indication of problems in the coordination of the two forms of activity within institutions (and within the workloads of individual academics), rather than of the lack of synergies between the two. One benefit may be that opportunities are provided for students to be in contact with research and possibly participate in it, thus providing important learning experiences. The research environment can also enrich the curriculum, and conversely interactions in the teaching space can inform and extend research agendas. Community engagement also fits logically with the other roles of the university, given that it is often connected directly to teaching and research activities. Arguments against unbundling, however, cannot rest on the necessary connection between teaching, research and service, as it is possible for these to be provided at a high level in separate institutions, as has historically been the case in countries such as France and Russia.

Nevertheless, there are other aspects of the multi-faculty institution that provide value. Cross-subsidization of courses allows for protection of areas that are not popular at a particular moment in time - but nevertheless have a long-term significance. The coexistence of different disciplinary areas can also provide important cross-fertilization of ideas for staff and students. The importance of multi-disciplinary, or possibly transdisciplinary work has been recognised as critical to solving the 'grand challenges' and 'wicked problems' facing global society today. (At the same time, it has to be acknowledged that the traditional institution, while bringing those from different disciplines together, also serves in some ways to pull them apart through its structures and practices.) Finally, in terms of academic work, Macfarlane (2007) has pointed to the dangers of contemporary developments in higher education in undermining 'academic citizenship' - the invisible work of academic staff in examining, peer review, writing references and numerous other functions that will be hard to continue in the absence of the all-round academic.

In summary, student learning can be seen to be significantly impacted by the process of unbundling, with the potential gains from personalization offset by the loss in the relational aspects of learning and opportunities for dialogue and broader experiential learning. In terms of the institution as a whole, empirical evidence is inconclusive, but 
there are nevertheless reasons for retaining confidence in the mutually beneficial coexistence of teaching, research and community engagement.

\section{$\underline{\text { Interaction }}$}

Of the three dimensions, interaction is the most clear-cut in its implications. The tendency of unbundling is unequivocally towards porosity, with an increasing weakening of the boundary between university and society. Most would agree that this is a positive tendency. Greater porosity signifies closer contact with issues of importance to communities outside the university, and the potential for universities to work with those issues for the benefit of society. It also entails a fuller communication of the knowledge produced within universities to the outside world. In terms of democratization of access, the implications are more ambiguous, as outlined above.

Nevertheless, despite limitations in terms of access, extensive interaction between university and society is clearly a desirable trend, increasing the relevance of HE, and the participation of broader segments of society in determining its priorities. However, the dynamic entailed in unbundling is what we might term hyperporosity, through which the boundaries between university and society become more than porous and begin to disappear altogether. This extreme form may in fact pose some dangers, and raises the prospect of some 'insulation' (Cowen 2012) being positive for a university. Some breathing space from the immediate priorities of government and industry is important in allowing the level of deep reflection necessary for breakthroughs in knowledge and understanding. Too great concern with the immediate and concrete impact of research (through the shift from mode 1 to mode 2 knowledge [Gibbons et al. 1994]) can be damaging for the more open 'blue skies' research that can bring even greater benefit for society in the long term. While endorsing porosity, therefore, some caution is needed in its extreme forms.

\section{Risks, responses and reversals}

Unbundling has been advocated for on the basis of providing greater efficiency, and thus allowing the expansion of higher education to continue with a sustainable funding base, while creating incentives for for-profit providers to enter the market. It has also been defended on pedagogical grounds, asserting the greater capacity of an unbundled system to empower learners and equip them with the competences needed in the labour market. However, analysis through the theoretical frame of value, function and interaction has revealed a number of worrying implications: first, the reduced leverage of institutions and systems to ensure equality of opportunity, and to promote the public good; second, the impoverishment of conceptions of learning in pared-down instruction-only models, and the loss of synergies between diverse elements of universities (between teaching, research and community engagement, and also between different disciplines); and third, while acknowledging the highly desirable nature of porous borders and extensive interaction, the need to maintain a distinct space and some autonomy for the activities of teaching and research. 
Unbundling reflects and promotes two broader dynamics in society: individualization and economization. It cherishes greater adaptability of learning towards individual goals, needs and lifestyles; it also places the economic at the centre of the picture, both in terms of cost efficiency of the educational process, and in terms of outcomes understood as maximization of salary and output. As such, it rests on deeply entrenched value divides in society. While arguments in favour of the unbundled university are often presented in terms of greater effectiveness, they very often reveal a different set of ends - those of, say, facilitating the insertion of workers into corporate jobs, and ensuring the development of new products for the market, rather than the furthering of human understanding, conscientization and social equality. We cannot therefore judge the unbundled institution against the traditional institution merely in terms of their effectiveness, but must also consider the purposes for which they are intended.

It has been argued in this article that there are three forms of 'bundle' in goods and services generally speaking: those in which consumers are forced to buy unwanted products (the tie-in form); those in which the constituent elements are brought together for time-saving or economic advantage (the convenience form); and those in which the constituent elements have a necessary or mutually beneficial relationship to one another (the interrelated form). At the kernel of the problem is the following question: is higher education of the former two types, in which case the financial benefits of unbundling will justify the process, as assumed by advocates such as Craig? Or is it of the latter type, meaning that separating out the parts will lead to an inevitable impoverishment of their functioning? Rather than a collection of songs (only some of which the consumer wants), a music album might be seen as a coherent whole, needing to be listened to from start to finish in order to fully appreciate its aesthetic qualities. Are the components of higher education in this way interrelated, interdependent and mutually reinforcing, with unbundling thereby entailing their undermining and impossible destruction?

With respect to the learning of students, there seems little doubt that the coexistence within the same environment of instruction, sources of information, pedagogical interaction, dialogue with other students and non-formal learning experiences are beneficial (though these may not need to be provided by the same staff members). With respect to the broader functions of the university, the implications are less conclusive, particularly because of the difficulties of providing an empirical basis for claims. Nevertheless, while it is certainly possible for high quality teaching and research to take place in separate institutions, there are strong arguments to support the idea that they are mutually beneficial, and are supported by and supportive of further functions of the institution relating to community engagement. These broader activities serve as a locus for the application of knowledge and understanding derived from teaching and research, and also as a conduit channelling the raw material of society's concerns into those processes.

There is no doubt that some of the ramifications of unbundling will only become clear over time, and with the greater maturation of the processes in practice within specific institutions and across systems. It has been suggested (e.g. Marginson 2016a), that only the elite universities will be able to continue as bundled institutions: for that small proportion of universities globally that is in the race for higher rankings, maintaining teaching and research and all the trimmings is of interest, but not for the others. Furthermore, it is not clear how unbundled forms of higher education will develop new 
institutional apparatuses, and thereby mitigate some of the challenges posed. It may be that institutions unbundle some aspects and retain others; and that some students continue to buy 'convenience bundles' (to save them having to purchase the different learning experiences separately) while others buy the no-frills version.

The practical problems associated with unbundling have led in some cases to different forms of 'rebundling'. Take, for example, the case of Kepler in Rwanda, outlined above. In order to support students to successfully complete the MOOCs that comprise their degree, residential accommodation is provided in the capital Kigali, along with tutorial support through resident instructors. For sure, the setup is still a far cry from the traditional campus university, but it is an indication that more extreme forms of unbundling are not considered viable, particularly in cases in which learners have not had high quality previous education. There are other instances of rebundling in the USA (Horn 2014), with integration of different elements such as mentoring and employer engagement so as to enhance synergies - indicating that unbundling and rebundling may be a cyclical rather than a linear process over history.

Many of the implications of unbundling will only become clear with time, and will no doubt change with the ongoing (and possibly unforeseen) developments in the political and economic sphere. The analysis above has shown that, while it is undoubtedly wrong to defend the traditional university simply by virtue of its existence and longevity, equally, there are a range of reasons to be sceptical about the proposed benefits of unbundling. Above all, we must avoid assuming that these trends are inevitable - as is often stated by advocates - and somehow free from value judgements. Universities - and all educational institutions - must respond to changing circumstances outside, but that does not mean accepting all forms of change whatever their value, and relinquishing their role also as agents and shapers of society. In so far as unbundling poses a threat to the central purpose of the university in furthering human understanding through openended enquiry (Collini 2012), there should certainly be resistance from all those associated with the institution - though not necessarily to save the traditional university for its own sake. Forming a coherent response to the challenge posed by unbundling requires deep and sustained attention to the nature and purpose of the institution, and society-wide deliberation on the values that should orient it.

\section{References}

Agarwal, A. (2013) Unbundled: Reimagining Higher Education. The Huffington Post, 9 December. Available at http://www.huffingtonpost.com/anant-agarwal/unbundledreimagining-higher-education b 4414048.html , accessed 9/2/17.

Anderson, R. (2006) British Universities Past and Present. London: Continuum.

Barber, M., Donnelly, K., \& Rizvi, S. (2013). An avalanche is coming. London, UK: Institute for Public Policy Research. Available at: http://www.ippr.org/files/images/media/files/publication/2013/04/avalancheis-coming_Mar2013_10432.pdf?noredirect=1 accessed 9/2/17. 
Biggs, J. (1999) What the Student Does: teaching for enhanced learning. Higher Education Research \& Development, 18 (1), 57-75.

Bok, D. (2003) Universities in the Marketplace: the commercialization of higher education. Princeton: Princeton University Press.

Bowen, W. G. (2013). Higher education in the digital age. Princeton: Princeton University Press.

Christensen, C. M., Horn, M. B., Caldera, L., \& Soares, L. (2011) Disrupting college: How disruptive innovation can deliver quality and affordability to postsecondary education. The Center for American Progress. Retrieved from http://www.americanprogress.org/issues/2011/02/disrupting college.html, $9 / 2 / 17$

Coleman, J. S. (1986). The idea of the developmental university, Minerva: A review of Science, Learning and Policy, 24(4), 476-494.

Collini, S. (2012). What are universities for? London: Penguin.

Cowen, R. (2012). Robustly Researching the Relevant: A Note on Creation Myths in Comparative Education. In L. Wikander, C. Gustaffson, and U. Riis (eds) Enlightenment, Creativity and Education: Polities, Politics, Performances, pp. 3-26. Rotterdam: Sense Publishers \& CESE.

Craig, R. (2015). College disrupted: The great unbundling of higher education. New York, NY: Palgrave Macmillan.

de Jonghe, A. (2005). Reorganising the teaching-research tension. Higher Education Management and Policy, 17(2), 61-76.

de Ridder-Symoens, H. (ed.) (1996) A History of the University in Europe (Volume 2). Universities in Early Modern Europe (1500-1800). Cambridge: Cambridge University Press.

Dianati, S. (2016) What do Massive Open Online Courses (MOOCs) Have To Do With 'Good' Education?: An Ideology Critique of MOOCs. Unpublished PhD thesis. Flinders University.

Gehrke, S., \& Kezar, A. (2015). Unbundling the faculty role in higher education: Utilizing historical, theoretical, and empirical frameworks to inform future research. In Higher Education: Handbook of Theory and Research (pp. 93-150). Springer International Publishing.

Gibbons, M., Limoges, C., Nowotny, H., Schwartzman, S., Scott, P., \& Trow, M. (1994). The new production of knowledge: The dynamics of science and research in contemporary societies. London: SAGE Publications Ltd. 
Grove, J. (2013) Troubling FX as Falmouth forces staff to go private. Times Higher Education, $3^{\text {rd }}$ January.

Hattie, J., and Marsh, H.W. (1996). The relationship between research and teaching-a meta-analysis. Review of Educational Research 66: 507-542.

Herk, M. (2015) Fixing Our Broken Colleges: Competency-Based Education and Reauthorizing the Higher Education Act. Committee for Economic Development. Available at: https://www.ced.org/blog/entry/fixing-our-broken-collegescompetency-based-education-and-reauthorizing-the, accessed 9/2/17.

Horn, M. (2014) Unbundling And Re-bundling In Higher Education. Forbes, 10 July. Available at: http://www.forbes.com/sites/michaelhorn/2014/07/10/unbundling-and-rebundling-in-higher-education/\#7ebaea2e79c2 , accessed 7/9/17.

Illich, I. (1973). Tools for conviviality. New York: Harper \& Row.

INEP (2015) Resumo Técnico. Censo da Educação Superior 2013. Brasília: INEP.

Kepler. (2016). Kepler: Higher education for all. http://www.kepler.org/. Accessed 7 June 2016.

Kerr, C. (1963). The Uses of the University. New York: Harper Torchbooks.

Kinser, K. (2002). Working at for-profit universities: The University of Phoenix as a new model. International Higher Education, (28), 13-14

Litan, R. E (2015) The case for 'unbundling' higher education. Brookings Institute. Available at

https://www.brookings.edu/articles/the-case-for-unbundling-higher-education/, accessed 9/2/17

Macfarlane, B. (2007) The Academic Citizen: the Virtue of Service in University Life. London: Routledge.

Macfarlane, B. (2011). The morphing of academic practice: Unbundling and the rise of the para-academic. Higher Education Quarterly, 65(1), 59-73.

Marginson, S. (2011). Higher education and public good. Higher Education Quarterly, 65(4), 411-433.

Marginson, S. (2016a) What holds the conglomerate university together? Paper presented at the Education, Practice and Society seminar, UCL Institute of Education, London, 16 November.

Marginson, S. (2016b) The dream is over: The Crisis of Clark Kerr's Californian Idea of Higher Education. Berkeley: University of California Press. 
McCowan T (2004) The Growth of Private Higher Education in Brazil: Implications for Equity and Quality. Journal of Education Policy, 19 (4), 453-472.

McCowan, T. (2016a) Forging radical alternatives in higher education: the case of Brazil. Other Education: the Journal of Educational Alternatives, 5 (2), 196-220.

McCowan, T. (2016b) Universities and the post-2015 development agenda: an analytical framework. Higher Education 72 (4), 505-523.

McCowan, T. (2016c) Three dimensions of equity of access in higher education. Compare: a Journal of Comparative and International Education. 46 (4), 645-665.

Paulson, K. (2002). Reconfiguring faculty roles for virtual settings. Journal of Higher Education, 73(1), 123-140.

Robertson, S. L. and Komljenovic, J. (2016a) Non-state actors, and the advance of frontier higher education markets in the global south. Oxford Review of Education, 42 (5).

Robertson, S. L. and Komljenovic, J. (2016b). Unbundling the University and Making Higher Education Markets. In A. Verger, C. Lubienski, \& G. Steiner-Kamsi (Eds.), World Yearbook in Education (Global edu). London: Routledge.

Schwartzman, S. (2004). Equity, Quality and Relevance in Higher Education in Brazil. Anais da Academia Brasileira de Ciências, 76 (1).

Selingo, J. J. (2013). College unbound: The future of higher education and what it means for students. Boston: New Harvest.

Troutt, W. E. (1979). Unbundling instruction: Opportunity for community colleges. Peabody Journal of Education, 56(4), 253-259.

UniversityNow (2017) Why we're different. Making higher education affordable. Available at: http://unow.com/making-education-affordable/ , accessed 9/2/17.

Vasagar, J. (2011) No frills university college offers half price degrees. The Guardian, 11 October. Available at: https://www.theguardian.com/education/2011/oct/17/coventry-universitycollege-half-price-degree, accessed 9/2/17.

Wang, W. K. S. (1975). The unbundling of higher education. Duke Law Journal, 1, 53-90.

Wildavsky, B. (2014). Evolving toward significance or MOOC ado about nothing. International Educator, May/June, 74-79. 